\title{
Estudo morfológico da polpa de molares de ratos Wistar frente a uma oclusão traumática experimental
}

\section{Morphological study of the pulp of Wistar rats molars under experimental occlusal interference}

\author{
Luiz Alberto Plácido PENNA* \\ Sigmar de Mello RODE**
}

\begin{abstract}
PENNA, L. A. P.; RODE, S. M. Estudo morfológico da polpa de molares de ratos Wistar frente a uma oclusão traumática experimental. Pesq Odont Bras, v. 14, n. 2, p. 159-164, abr./jun. 2000.

As alterações morfológicas pulpares, decorrentes de um estímulo externo experimental (interferência oclusal), foram estudadas, em nivel de microscopia de luz. Utilizaram-se restaurações de amálgama, em sobreoclusão nos primeiros molares superiores direitos de dez ratos Wistar, divididos em 3 grupos e sacrificados por perfusão transcardíaca com formol a 10\%, aos 10, 20 e 30 dias. A avaliação foi feita nos molares inferiores direitos (lado experimental) e esquerdos (lado controle). As peças ósseas após descalcificação em solução de EDTA associada às microondas, seguiram técnica histológica de rotina e coloração por hematoxilina-eosina e tricrômico de Mallory. Verificou-se no lado controle uma reação intensa caracterizada por um posicionamento atípico dos odontoblastos, seguida pelo aparecimento de cálculos pulpares e posteriormente por uma aparente e uniforme acomodação tecidual em toda a polpa, com moderada incidência de fibras colágenas. No lado experimental, as alterações foram similares parecendo, porém, aumentar com o tempo, principalmente aos 30 dias, onde a imagem histológica era semelhante à do lado controle aos 10 dias. Os resultados obtidos permitiram concluir que a interferência oclusal provocou alterações no tecido conjuntivo pulpar tanto no lado experimental como no controle e que as mesmas foram proporcionais à direção dos movimentos mandibulares.
\end{abstract}

UNITERMOS: Oclusão dentária; Oclusão dentária traumática; Polpa dentária.

\section{INTRODUÇÃO}

A oclusão não é meramente uma intercuspidação dos dentes, mas sim um relacionamento integrado dos componentes do sistema estomatognático. Quando há uma quebra do equilíbrio deste sistema os efeitos se fazem sentir também em todo o organismo, sendo o trauma oclusal um de seus fatores etiológicos mais conhecidos. De acordo com BARROS; RODE ${ }^{1}$ (1995) é perfeitamente natural que cada especialidade enfoque a oclusão dentro dos limites de suas necessidades, o que provoca controvérsias no ensino e estudo do assunto; além disso a responsabilidade do cirurgião-dentista diante dos problemas das disfunções craniomandibulares é: reconhecer, diagnosticar, tratar e, principalmente, evitar.

Os efeitos de interferências oclusais no sistema mastigatório têm sido estudados amplamente com protocolos experimentais clínicos e/ou laboratoriais, nos seus mais diversos componentes podendo causar alterações no padrão de contração muscular e no padrão dos movimentos mandibulares, estando ou não associadas a sinais e sintomas clínicos.

Sabe-se que os efeitos da interferência oclusal nos tecidos periodontais têm sido intensamente estudados e relatados na literatura ${ }^{4,6,7,8}$. Surpreendentemente em relação à polpa, existem poucos trabalhos ${ }^{3,9,13,14}$. Clinicamente, a intimidade e a dependência biológica entre polpa e dentina, fazem com que qualquer estímulo, mesmo que na superficie do esmalte, tenha repercussão na polpa, como por exemplo, processos de defesa caracterizados por uma reação inflamatória e/ou deposição de dentina terciária, culminando com modificações de natureza degenerativa. Toda a polpa, e principalmente seu componente extracelular, além das modificações que ocorrem com a idade e que alteram fundamentalmente a capacidade de resposta tecidual, está sujeita à ação dos estímulos externos cuja intensidade e freqüência são muito variá-

\footnotetext{
* Mestre e Doutor do Departamento de Prótese Buco-Maxilo-Facial; ** Professor Adjunto do Departamento de Materiais Odontológicos e Prótese - Faculdade de Odontologia de São José dos Campos da UNESP.
} 
PENNA, L. A. P.; RODE, S. M. Estudo morfológico da polpa de molares de ratos Wistar frente a uma oclusão traumática experimental.

Pesq Odont Bras, v. 14, n. 2, p. 159-164, abr./jun. 2000.

veis $^{10}$, o que nos leva a crer, portanto, ser possivel que estas alterações teciduais também estejam presentes quando da ocorrência de uma oclusão traumática devida a uma interferência oclusal experimental.

\section{MATERIAIS E MÉTODOS}

Foram utilizados para este estudo 10 ratos machos albinos da linhagem Wistar (Rattus norvegicus), com peso corpóreo médio de $300 \mathrm{~g}$, divididos aleatoriamente em 3 grupos, sendo um com 4 animais e os outros 2 com 3 animais cada. Os animais foram sacrificados aos 10, 20 e 30 dias, tendo sido utilizado o grupo maior para o período mais longo.

Cada animal recebeu no primeiro molar da hemimaxila direita uma restauração de amálgama, a título de interferência oclusal, ficando o lado esquerdo, sem intervenção, para controle. Os animais após pesagem, sofreram anestesia geral através de injeção intraperitoneal de uma solução de Rompum (Bayer do Brasil) com ketamina $50 \mathrm{mg}$ (Ketalar, Parke-Davis, São Paulo) na proporção $1: 1$, sendo $0,2 \mathrm{ml}$ para cada $100 \mathrm{~g}$ de peso corpóreo.

Após a anestesia foram colocados na posição de decúbito dorsal, em mesa de trabalho de aço inoxidável adaptada para o experimento conforme descrito por SATO ${ }^{12}$ (1991), e todas as manobras operatórias foram realizadas com auxílio de um microscópio cirúrgico (Modelo MC-M5 D.F. Vasconcelos, Brasil), com aumento de 16 vezes.

Os molares selecionados foram limpos e secos e, em seguida, fez-se um preparo do tipo classe I em suas superficies oclusais, utilizando-se para a abertura inicial do preparo uma broca esférica $n^{\circ} \frac{1}{4}$, de aço para baixa-rotação, sob refrigeração e, uma tronco-cônica invertida $n^{\circ} 33 \frac{1}{2}$ do mesmo material, também para baixa-rotação, com a finalidade de conferir adequada retenção ao preparo.

Após esse procedimento foi feita a lavagem abundante com água, seguida de secagem através de jatos de ar. A seguir foi preparada uma porção de amálgama, segundo as especificações do fabricante. O material foi inserido na cavidade com o auxilio de um porta-amálgama pequeno utilizado para obturações retrógradas em cirurgias apicais, em quantidade suficiente para que a restauração ficasse com aproximadamente $0,5 \mathrm{~mm}$ de altura acima da superficie oclusal dos molares. A condensação foi efetuada com a ajuda de condensadores de pequeno diâmetro e o brunimento com a ponta de um aplicador de hidróxido de cálcio.

Os animais foram freqüentemente sedados e pesados para verificação de ocorrência de possivel alteração na alimentação e perdas das restaurações. As eventuais reposições foram imediatamente realizadas, sob as mesmas condições das iniciais. Quando do sacrificio, foram sedados por inalação de éter etílico, pesados e anestesiados como anteriormente, quando foram submetidos a uma perfusão transcardíaca com uma solução de formol a $10 \%$ em tampão fosfato $0,1 \mathrm{M}$ e $\mathrm{pH} 7,3$, garantindo assim uma melhor fixação dos tecidos. Os animais foram decapitados e para evitar possiveis interferências do preparo e da restauração de amálgama na polpa, foram dissecadas as mandibulas para que pudessem ser analisados os dentes antagonistas aos preparados.

As peças ósseas foram descalcificadas em solução de EDTA a 17\% em água destilada (Sigma, USA) em forno de microondas segundo a técnica desenvolvida por RODE et al. ${ }^{11}$ (1996) que consistiu em colocar as 20 hemi-mandíbulas, em "becker" com a solução de EDTA imerso parcialmente em uma cuba de vidro com água e gelo picado para retardar o aumento da temperatura e, conseqüentemente, incrementar o tempo de atuação das microondas. O grau de descalcificação das estruturas mineralizadas foi controlado periodicamente por meio de radiografias de todos os espécimes: de 4 em 4 horas no início e diminuindo com o tempo de desmineralização para verificação de radiopacidade nos mesmos até que se obtivesse a total radioluscência na região dos molares.

Isto feito, o material seguiu técnica histológica de rotina para parafina. Cortes seriados de $4 \mu \mathrm{m}$ de espessura, foram corados em $\mathrm{H}$. E. e tricrômico de Mallory.

\section{RESULTADOS E DISCUSSÃO}

A utilização de roedores, mais especificamente ratos, para um trabalho de pesquisa, apresenta vantagens, tais como: facilidade de manipulação, tempo de vida, facilidade de reprodução, tamanho, peso, custo, armazenagem, alimentação, controle e previsibilidade.

Uma das situações clínicas mais comuns ao profissional é, quando ao restaurar um ou mais elementos dentários, provoca uma mudança do padrão oclusal muitas vezes levando a uma interferência oclusal, que pode provocar lesões ou alterações no sistema estomatognático ${ }^{1}$. Portanto, este fato merece especial atenção não só dos clínicos, mas também de trabalhos de pesquisa.

A literatura descreve vários dispositivos utilizados para indução de forças às estruturas dentárias, com a finalidade de produzir interferência oclusal: fio de aço, em forma de um arco palatino, unindo os primeiros molares superiores, criaram 
PENNA, L. A. P.; RODE, S. M. Estudo morfológico da polpa de molares de ratos Wistar frente a uma oclusão traumática experimental.

Pesq Odont Bras, v. 14, n. 2, p. 159-164, abr./jun. 2000.

condições oclusais propícias ao desenvolvimento de interferência oclusal ${ }^{4,6}$; fio de aço cortado em pequenos pedaços, de maneira que pudessem ser fixados como pinos e criar situações de interferência oclusal, também foi descrito na literatura ${ }^{3,6,12}$; aparelhos protéticos, na forma de incrustações metálicas do tipo MOD, para a indução de interferência oclusal'; aparelhos ortodônticos fixos, criando e induzindo forças intrusivas ${ }^{13}$. Outras formas de provocar interferência oclusal foram descritas na literatura, como a colocação de resina composta na superficie oclusal de dentes de $\operatorname{ratos}^{8}$, ou a cimentação de uma placa de resina sobre a superficie oclusal de dentes de ratos ${ }^{7}$.

A literatura nos mostrou que diversos autores $^{6,9}$, haviam utilizado com sucesso o amálgama. Por ser um material de grande utilização em Odontologia, e que muitas vezes por um descuido do profissional leva a uma interferência oclusal por uma escultura inadequada, nos levou a escolher este material. Para tanto confeccionamos as cavidades bastante amplas e retentivas, para evitar a queda da restauração. SATO ${ }^{12}$ (1991) não obteve sucesso no uso do amálgama, provavelmente por uma retenção deficiente do preparo, e preferiu optar por outro método para interferência oclusal.

Observamos também que mesmo sem ter sido executado qualquer polimento, os amálgamas de todos os animais apresentavam superficies bastante brilhantes, denotando a atividade parafuncional (bruxismo), o que também foi comprovado pelo intenso barulho de ranger de dentes que os animais constantemente apresentavam.

O fato dos animais, no presente estudo, permanecerem com sua dieta normal, sugere uma capacidade adaptativa do sistema mastigatório. Em nenhum dos trabalhos consultados na literatura foi relatado ter havido redução de peso dos animais durante o periodo experimental, apesar das alterações impostas à oclusão, o mesmo ocorrendo em nosso trabalho.

Para a desmineralização preferimos utilizar o EDTA $^{7,11,12}$, por ser uma substância que preserva melhor os tecidos, além de termos conseguido uma grande redução de tempo por associar microondas à descalcificação, de acordo com a técnica de RODE et al..$^{11}$ (1996).

Utilizamos no nosso trabalho um método de controle do nivel de descalcificação dos espécimes, através de séries de radiografias, pelas quais observávamos o grau de radiopacidade das peças no decorrer do processo, método este que mostrou ser mais preciso do que o da transfixação dos tecidos descalcificados por uma agulha, utilizado por RODE et al. ${ }^{11}$ (1996).
A ação de uma interferência oclusal sobre os tecidos tem sido preocupação de vários autores na literatura, onde podemos destacar um estudo amplo sobre as alterações periodontais ${ }^{2,4,6,7,9}$ que nos serviram de suporte para a metodologia e um outro grupo de autores que estudaram especificamente a ação sobre a polpa ${ }^{2,3,5,8,9,13,14}$. Embora LANDAY et $a l .{ }^{9}$ (1970) tenham encontrado reação pulpar por interferência oclusal somente após sete meses, provavelmente por utilizar uma interferência de baixa intensidade, os demais autores estudados encontraram alterações morfológicas pulpares em tempos menores, o mesmo ocorrendo em nosso trabalho.

Encontramos alterações morfológicas no lado controle e no lado experimental, assim como BHASKAR; ORBAN $^{2}$ (1955) e STENVIK; MJÖR ${ }^{13}$ (1970). Estes aspectos se devem, provavelmente, a uma alteração no padrão mastigatório dos animais causada pela restauração em sobreoclusão, a qual provocou um bruxismo intenso, afetando também o lado controle, inicialmente de maneira mais forte e com uma resposta tecidual mais intensa (Figura 1). Este fato deve ter sido causado pela inclinação dos molares dos ratos e, por um componente lateral da força quando do bruxismo, como já observado por DOTTO et al. ${ }^{4}$ (1966). Posteriormente houve uma uniformização da resposta tecidual do lado controle, devida, provavelmente, a uma acomodação do padrão mastigatório dos animais, tornando-o habitual.

Em contrapartida, inicialmente, o lado experimental foi afetado de modo mais suave, porém contínuo, pela restauração em excesso, o que provocou uma resposta tecidual crescente, de acordo com os tempos estudados.

As respostas pulpares, de maneira geral, caracterizaram-se por uma desorganização da camada odontoblástica, com odontoblastos típicos e atípicos (Figura 1), o que foi também observado por outros autores ${ }^{3,5,13,14}$.

Foi digno de nota, no lado mesial do grupo controle, a forma cilíndrica com núcleos elípticos dos odontoblastos, podendo sugerir alta atividade de sintese e indicando, portanto, uma resposta mais intensa à agressão, enquanto no lado distal, estas células eram cubóides com núcleos esféricos, podendo sugerir baixa atividade de sintese. Esta situação foi observada no lado controle, aos dez e vinte dias e, no lado experimental aos trinta dias, levando-nos a supor ser a alteração no odontoblasto diretamente proporcional à direção e intensidade da força aplicada.

A presença de cálculos pulpares, observada aos vinte e trinta dias no lado controle (Figura 2), suge- 
PENNA, L. A. P.; RODE, S. M. Estudo morfológico da polpa de molares de ratos Wistar frente a uma oclusão traumática experimental.

Pesq Odont Bras, v. 14, n. 2, p. 159-164, abr./jun. 2000.

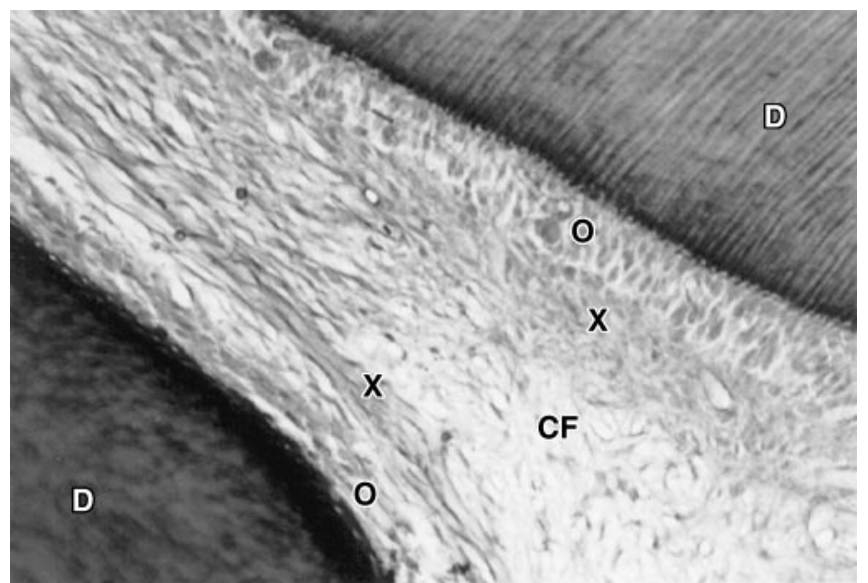

FIGURA 1 - Fotomicrografia do lado controle, 10 dias, onde pode-se observar na polpa, a partir da dentina (D), uma camada de odontoblastos $(\mathrm{O})$, um tecido conjuntivo com grande quantidade de fibras colágenas (X) e um tecido conjuntivo frouxo $(\mathrm{CF})$. No lado distal (esquerda da foto) a camada de fibras colágenas está menos condensada do que no lado mesial (direita da foto). Tricrômico de Mallory (430 X).

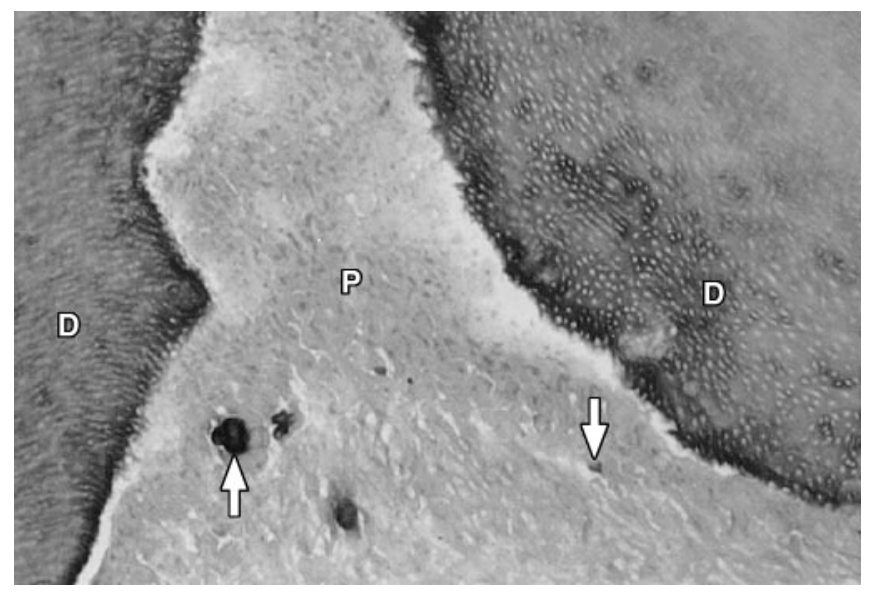

FIGURA 2 - Fotomicrografia do lado controle, 20 dias, onde pode-se observar a dentina (D) e a polpa (P) com a presença de cálculos (seta). Tricrômico de Mallory $(430 \mathrm{X})$.

re uma resposta mais imediata da polpa à agressão (caracterizada pela componente lateral). LANDAY et al. ${ }^{9}$ (1970) e STENVIK; MJÖR ${ }^{13}$ (1970), relataram a presença de cálculos como resposta pulpar à interferência oclusal.

Em nosso trabalho, de maneira geral, os tecidos pulpares responderam à agressão com um aumento significativo na quantidade de fibras colágenas, o que também foi observado por TRONSTAD; LANGELAND $^{14}$ (1971), com interferência oclusal e, por $\operatorname{RODE}^{10}$ (1992), com lesão de cárie. No lado

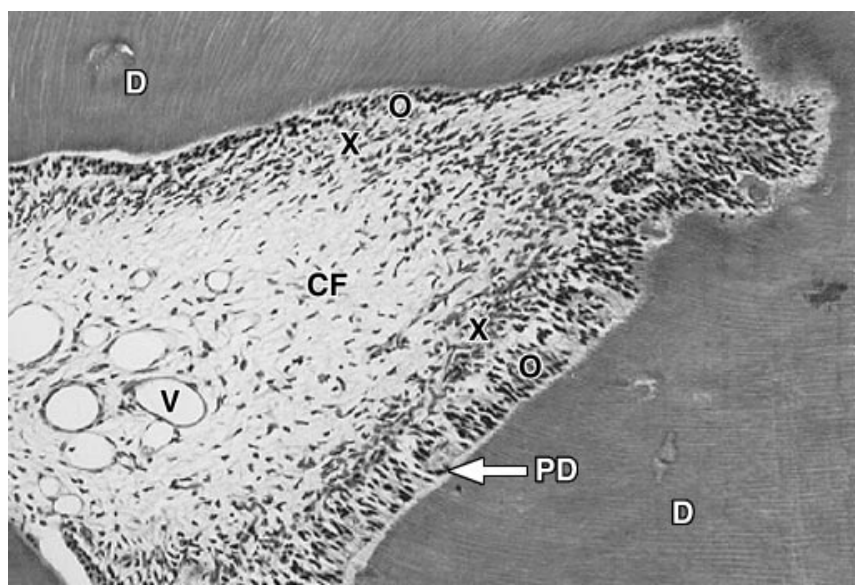

FIGURA 3 - Fotomicrografia do lado experimental, 20 dias, onde pode-se observar na polpa, a partir da dentina (D), uma região de pré-dentina (PD), uma camada de odontoblastos $(\mathrm{O})$, um tecido conjuntivo com fibras colágenas $(\mathrm{X})$ e um tecido conjuntivo frouxo $(\mathrm{CF})$ vascularizado (V). No lado mesial (direita inferior da foto), vê-se a camada de odontoblastos mais espessa do que no lado distal (superior da foto). H. E. (200 X).

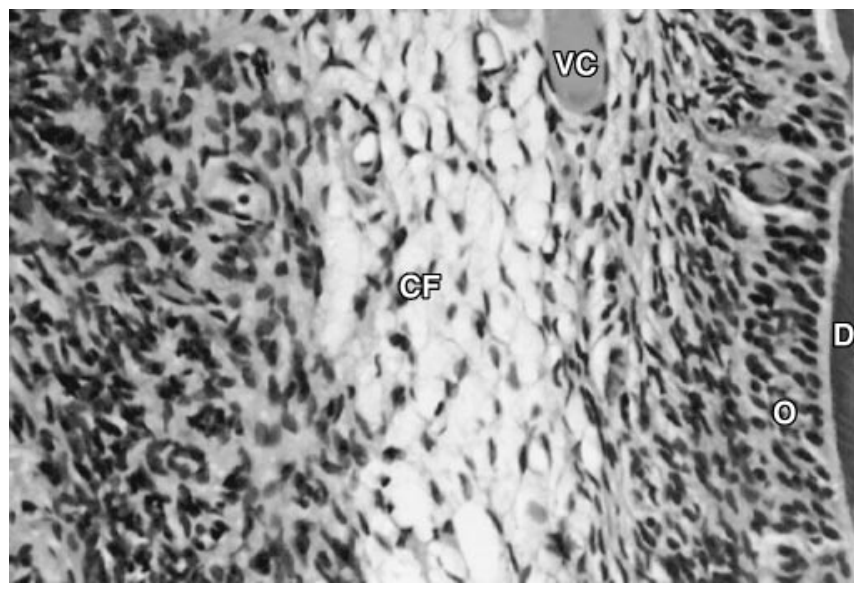

FIGURA 4 - Fotomicrografia do lado experimental, 30 dias, onde pode-se observar na polpa, a partir da dentina (D), a camada de odontoblastos (O) e um tecido conjuntivo frouxo $(\mathrm{CF})$ com a presença de vasos congestos (VC) no seu interior. H. E. (430 X).

controle, inicialmente, as fibras colágenas por nós observadas concentraram-se abaixo da camada odontoblástica, com muitos fibroblastos em seu interior, formando como que uma "barreira de proteção fibrosa" à agressão sofrida pela polpa (Figura 3). Este acúmulo de células também foi relatado por STENVIK; MJÖR ${ }^{13}$ (1970) e HAUGEN; MJÖR (1975). No lado experimental esta chamada "barreira" apareceu aos 30 dias (Figura 4).

Ainda como resposta a uma agressão por um trauma oclusal, TRONSTAD; LANGELAND ${ }^{14}$ (1971) 
PENNA, L. A. P.; RODE, S. M. Estudo morfológico da polpa de molares de ratos Wistar frente a uma oclusão traumática experimental.

Pesq Odont Bras, v. 14, n. 2, p. 159-164, abr./jun. 2000.

e HAUGEN; MJÖR ${ }^{5}$ (1975), descreveram uma diminuição da polpa coronária, pela formação de uma dentina terciária, fato este não estudado em nosso trabalho, embora tivéssemos constantemente observado alterações na camada de pré-dentina.

Em virtude do que foi relatado e discutido, concordamos com as afirmações de $\operatorname{RODE}^{10}$ (1992), de que a interdependência biológica das diversas estruturas do dente faça com que a interferência oclusal, ainda que apenas na superficie do esmalte, tenha repercussão na polpa, levando, conseqüentemente, a alterações degenerativas que podem, dependendo da intensidade e duração do estímulo, comprometer sua vitalidade, tornando este fato muito importante por sabermos ser clinicamente dificil promover o correto formato e ajuste de uma restauração em amálgama.

\section{CONCLUSÕES}

Com base nos resultados obtidos nas condições desta pesquisa, podemos concluir:

1. A interferência oclusal provocou alterações morfológicas no tecido conjuntivo pulpar tanto no lado experimental como no controle.

2. A interferência oclusal levou a uma reação da polpa, caracterizada por alteração na camada de odontoblastos e moderado aumento na quantidade de fibras colágenas. No lado controle estas reações ocorreram de forma mais precoce do que no lado experimental.

3. No lado controle, oposto à interferência, as alterações morfológicas foram proporcionais à direção dos movimentos mandibulares que inicialmente foram mais intensas no lado mesial, e com resposta moderada, semelhante em ambos os lados, no decorrer do experimento.

4. As alterações morfológicas no lado da interferência, foram inicialmente mais discretas, intensificando-se no decorrer do experimento.

\section{AGRADECIMENTO}

À Profa. Miriam Rubio Faria pela colaboração, na técnica histológica.

PENNA, L. A. P.; RODE, S. M. Morphological study of the pulp of Wistar rats molars under experimental occlusal interference. Pesq Odont Bras, v. 14, n. 2, p. 159-164, abr./jun. 2000.

Pulpal morphological alterations in mandibular molars of rats, resulting from an experimental external stimulus (occlusal interference), were studied using light microscopy. We placed amalgam restorations in supraocclusion in the right superior first molars of 10 Wistar rats divided into three groups, which were sacrificed by transcardiac perfusion with 10\% formalin, after 10, 20 and 30 days. The evaluation of the right (experimental side) and left (control side) inferior molars was made after decalcification of the bony specimens with EDTA solution associated with microwaves, followed by routine histologic technique and staining with $\mathrm{HE}$ and Mallory's Trichrome. On the control side, an intense reaction characterized by an atypical positioning of the odontoblasts was observed, followed by the appearance of pulp stones and, subsequently, by an apparent and uniform accommodation of the tissue in the whole pulp, with moderate incidence of collagenous fibers. On the experimental side, the alterations were similar, but they apparently increased with time, specially after 30 days, when the histologic image was similar to that of the control side after 10 days. We can conclude that the occlusal interference induces alterations in the pulpal connective tissue both on the experimental side and on the control side, and they are proportional to the direction of the mandibular movements.

UNITERMS: Dental occlusion; Dental occlusion, traumatic; Dental pulp.

\section{REFERÊNCIAS BIBLIOGRÁFICAS}

1. BARROS, J. J.; RODE, S. M. Tratamento das disfunções craniomandibulares - ATM. São Paulo : Ed. Santos, 1995. $371 \mathrm{p}$.

2. BHASKAR, S. N.; ORBAN, B. Experimental occlusal trauma. J Periodontol, v. 26, p. 270-284, 1955.

3. COOPER, M.; LANDAY, M.; SELTZER, S. The effects of excessive occlusal force on the pulp: heavier and long term forces. J Periodontol, v. 42, n. 6, p. 353-359, Jun 1971.

4. DOTTO, C. A.; CARRANZA, F. A.; ITOIZ, M. E. Efectos mediatos del trauma experimental en ratas. Rev Asoc Odont Argent, v. 54, p. 48-51, 1966.

5. HAUGEN, E.; MJÖR, I. A. Pulpal reactions to attrition. J Endod, v. 1, n. 1, p. 12-14, Jan 1975.

6. ITOIZ, M. E.; CARRANZA Jr., F. A.; CABRINI, R. L. Histolo- gic and histometric study of experimental occlusal trauma in rats. J Periodontol, v. 34, p. 305-314, 1963.

7. KUMAZAWA, M.; KOHSAKA, T.; YAMASAKI, M. et al. Effect of traumatic occlusion on periapical lesions in rats. $\mathbf{J}$ Endod, v. 21, n. 7, p. 372-375, Jul 1995.

8. KVINNSLAND, S.; KRISTIANSEN, A. B.; KVINNSLAND, I.; HEYERAAS, K. J. Effect of experimental traumatic occlusion on periodontal pulpal and blood flow. Acta Odontol Scand, v. 50, n. 3, p. 211-219, 1992.

9. LANDAY, M. A.; NAZIMOV, H., SELTZER, S. The effects of excessive occlusal force on the pulp. J Periodontol, v. 41, p. 3-11, Jan 1970.

10. RODE, S. M. Estudo comparativo ultra-estrutural da matriz extracelular do tecido conjuntivo pulpar de dentes humanos, hígidos, cariados e restaurados. 
PENNA, L. A. P.; RODE, S. M. Estudo morfológico da polpa de molares de ratos Wistar frente a uma oclusão traumática experimental.

Pesq Odont Bras, v. 14, n. 2, p. 159-164, abr./jun. 2000.

São Paulo, 1992, 73 p. Tese (Doutorado em Dentística) Faculdade de Odontologia, Universidade de São Paulo.

11. RODE, S. M.; FARIA, M. R.; MONTEIRO, M. P. O uso de microondas para descalcificação de tecidos mineralizados da mandíbula de ratos. Rev Odontol Univ São Paulo, v. 10, n. 1 , p. 15-18, Jan/Mar 1996.

12. SATO, E. F. L. Estudo morfológico das alterações teciduais do terço apical e periápice de molares de ratos após o tratamento endodôntico, tendo como variá- vel condições oclusais diversas. São Paulo, 1991, 147 p. Tese (Doutorado em Endodontia) Faculdade de Odontologia, Universidade de São Paulo.

13. STENVIK, A.; MJÖR, I. A. Pulp and dentine reactions to experimental tooth intrusion. Am J Orthod, v. 57, n. 4, p. 370-385, April 1970.

14. TRONSTAD, L.; LANGELAND, K. Effect of attrition on subjacent dentin and pulp. J Dent Res, v. 50, n. 1, p. 17-30, Feb 1971.

Recebido para publicação em 25/11/99

Enviado para reformulaçãom em 13/12/99

Aceito para publicação em 21/03/00 